\title{
SOBRE LA TRANSMISIBILIDAD DE LA ACCIÓN INDEMNIZATORIA DEL DAÑO MORAL EN SEDE LABORAL: UNA PROPUESTA EN BASE AL PRINCIPIO PROTECTOR
}

On the Transmissibility of the Action to Claim Non-Pecuniary Damages Compensation in the Labor Law: A Proposal Based in the Protective Principle

\author{
BENJAMÍn ANDRÉS VICO GÁRATE* \\ Pontificia Universidad Católica de Chile
}

RESUMEN

El estudio discute la existencia de un caso difícil o dudoso en cuanto a la transmisibilidad de la acción para solicitar la indemnización del daño moral. Frente a ello se establece una solución en el derecho laboral, desde que a la luz del principio protector resulta más favorable al trabajador abogar por el carácter transmisible de la acción. Así, se ofrece una propuesta para fortalecer la argumentación estrictamente civil en el tema, en aras de conservar el razonamiento actual de la Corte Suprema.

PALABRAS CLAVE

Daño moral, transmisibilidad, principio protector

\section{ABSTRACT}

The essay discusses the difficult or doubtful nature of the case regarding the transmissibility of a legal action to claim non-pecuniary damages compensation, and puts forward a solution which draws from the labor law's protective principle, designed to act in benefit of the employee. A proposal regarding the transmissibility of the action is offered to strengthen the civil argumentation framework applied until now for the purposes of creating a more consistent way of resolving these cases before the Supreme Court.

\section{KEYWORDS}

Non-Pecuniary Damage, Transmissibility, Protective Principle

\section{Introducción}

Décadas han pasado desde que nuestra Corte Suprema resolviera reconocer la indemnización del daño moral, desde entonces se ha sido testigo tanto de la consagración de esta institución en el ordenamiento positivo ${ }^{1}$, como de las problemáticas propias que ella ha traído aparejadas. Dentro de estas últimas se puede mencionar la dificultad de determinar el quantum indemnizatorio, lo discutible de las personas jurídicas como sujetos de este tipo de daño, su procedencia en las acciones colectivas, e incluso se ha debatido sobre su debida nomenclatura y definición ${ }^{2}$. Asimismo, y más recientemente, surgió -en la praxis-el problema sobre su carácter transmisible, en otras palabras: ¿pueden los herederos reclamar la

\footnotetext{
* Estudiante de Derecho de la Pontificia Universidad Católica de Chile. Ayudante de la cátedra Derecho del Trabajo de la profesora Carmen Domínguez Soto. Dirección postal: Miguel Claro 444 d. 23-C, Providencia, Ciudad de Santiago, Chile. Dirección electrónica: bavico@uc.cl.

${ }^{1}$ Por ejemplo, en la Ley 16.744 sobre Accidentes del Trabajo; como también en la Ley 19.469 sobre protección de los derechos de los consumidores (LPC).

2 Sobre el quantum indemnizatorio véase Domínguez (2000), pp. 663-713; sobre el daño moral en personas jurídicas véase Domínguez (2000), pp. 719-728 y Barrientos (2007), pp. 135-138; sobre la nomenclatura de la institución consúltese Barrientos (2008), pp. 85-106; y sobre su procedencia en las acciones colectivas cabe mencionar que la reforma a la LPC, que permite la indemnización del daño moral en las acciones colectivas, entró en vigencia el 14 de marzo de 2019, por lo que se espera que pronto exista doctrina y jurisprudencia del tema.
} 
indemnización del daño moral sufrido por el causante cuando este no pudo ejercer la debida acción indemnizatoria en vida? ¿podrían los hijos de un trabajador, víctima de un accidente laboral fatal, conseguir una indemnización por el sufrimiento padecido por su padre a instantes de su deceso?

Las respuestas a dichas interrogantes parecieron haber quedado resueltas en 2016. Pues en sentencia de fecha 27 de diciembre de dicho año, nuestro excelentísimo tribunal, conociendo de un recurso de unificación de jurisprudencia caratulado "Quezada con Colmenares Werner" ${ }^{3}$, resolvió por atribuirle el carácter de transmisible a dicha acción en el ámbito del Derecho del Trabajo. Consecuentemente, los herederos del trabajador, víctima de un accidente fatal, consiguieron una indemnización producto del daño extrapatrimonial sufrido por este en vida. Mas esta solución fue aparente para el resto del sistema jurídico, pues fuera del ámbito laboral solo bastaron un par de años para que la Corte Suprema fallara de forma contraria, es decir, declarando el carácter intransmisible de la acción ${ }^{4}$.

El presente estudio se dedicará a realizar una revisión de la doctrina y jurisprudencia sobre el tópico. Lo anterior en búsqueda de encontrar argumentos para continuar sosteniendo la posición de la transmisibilidad en materia laboral en aras de fortalecer la argumentación civil del recurso de unificación, pues un cambio de paradigma en la materia es altamente probable dado las características de la problemática. Para ello, el trabajo se dividirá en tres partes: una primera parte expositiva, donde se darán a conocer las diferentes posiciones que ha debatido la doctrina frente al tema, con su respectiva reproducción en la jurisprudencia; una segunda, en la que se demostrará que se está ante un caso difícil o dudoso que pone en riesgo la certeza jurídica; y por último, se finalizará con un acápite argumentativo en el que se persuadirá al jurista sobre la tesis en estudio: la acción para perseguir la indemnización del daño moral es transmisible en sede laboral por aplicación del principio protector.

\section{Alcances previos}

Antes de continuar es menester realizar algunos alcances. Por una parte, preciso es que el lector tenga presente que se discutirá sobre el carácter transmisible o intransmisible de la acción por daño moral. Es decir, se tratará de la acción que los herederos pretenden ejercer vía iure hereditatis ante los tribunales por el perjuicio extrapatrimonial sufrido por el causante antes de su muerte. No así de la posibilidad de ejercer la acción vía iure propio, en otras palabras, que los herederos soliciten una indemnización por el daño moral que sufrieron ellos personalmente a consecuencia de la muerte del causante con quien tenían un especial vínculo afectivo. Así se comprende la diferencia entre la víctima directa, quien sufre el daño y es el primitivo titular de la acción; y las víctimas por repercusión o rebote, correspondientes a familiares de la víctima directa que pueden ejercer su propia acción distinta a aquella que le corresponde al directamente perjudicado.

Tampoco se abordarán aquellos casos en que la víctima fallece luego de haber ejercido la acción de indemnización de perjuicios por daño moral en juicio. Pues la mayoría entiende que dicha acción se transmite a los herederos desde que el artículo 5 del Código de Procedimiento Civil así lo permite, o bien se admite que el mandatario judicial continúe hasta terminar el encargo para luego reclamar lo obtenido en el proceso ${ }^{5}$.

\footnotetext{
${ }^{3}$ Corte Suprema, Rol № 33990-16, de 27 de diciembre de 2016. El recurso de unificación de jurisprudencia se incorporó a nuestra legislación en 2009, es resuelto por la Corte Suprema, y pretende dar una respuesta concreta ante dos interpretaciones distintas que han tenido los tribunales superiores de justicia frente a una materia determinada en ámbito laboral. La sentencia en comento causó un gran debate en la doctrina, siendo objeto de dos comentarios de jurisprudencia de Hernán Corral en El Mercurio Legal, titulados "Transmisibilidad de la indemnización por daño moral" y "Una vez más sobre la transmisibilidad de la indemnización por daño moral". Así como también de otros comentarios en BARRIA (2018), pp. 112-117; PALAVECINO (2018), pp. 119-127; RIOSECO (2018), pp. 129-139.

${ }^{4}$ Corte Suprema, Rol № 21614-17, de 22 de mayo de 2018.

${ }^{5}$ Así lo ha entendido la jurisprudencia, en Corte Suprema, Rol № 27948-17, de 4 de abril de 2019.
} 
Por otra parte, no está demás contextualizar al lector sobre el origen de la problemática en la praxis. En este sentido, si bien la discusión sobre el carácter transmisible de la acción en cuestión no es privativa de la sede laboral ${ }^{6}$, es justamente allí donde alcanza su mayor éxtasis. Dentro de la esfera del derecho del trabajo, previo a la Ley 21.018 de 2017, la competencia de los juzgados laborales en casos de accidente del trabajo estaba redactada de tal forma que hacía a muchos entender que el legitimado activo para entablar una acción por indemnización de perjuicios era exclusivamente el trabajador, con exclusión de sus herederos por más que actuasen como los sucesores legales del causante.

En este sentido, los tribunales de primera instancia tendían a declararse incompetentes cada vez que se entablaba una acción de indemnización de perjuicios por los causahabientes un trabajador fallecido. Lo anterior bajo la argumentación de que al no existir un contrato de trabajo entre los demandantes y la empresa demandada, se estaría bajo un régimen de responsabilidad extracontractual donde los tribunales competentes son los civiles, mas no los laborales. La argumentación en cuestión resulta del todo razonable cuando los causahabientes del trabajador entablaban la acción de indemnización de perjuicios a iure propio, es decir, por el daño moral que ellos sufrieron debido a la muerte de su familiar, pues a todas luces no existe una relación laboral entre las partes susceptible de ser conocida en sede del trabajo ${ }^{7}$. Sin embargo, cuando los causahabientes actúan vía iure hereditatis la argumentación de los tribunales pierde sentido, pues los demandantes estarían actuando como los sucesores legales del trabajador fallecido, es decir, entablan la acción en nombre de una de las partes de la relación laboral.

Paradójicamente los tribunales laborales de primera instancia se declaraban incompetentes también en el segundo caso: cuando los demandantes actuaban como sucesores legales del trabajador fallecido producto de un accidente laboral. Esto llevó a dos consecuencias que buscaron resolver la problemática procesal, una judicial y otra legislativa. Naturalmente la primera consistió en que las Cortes de Apelaciones corrigieron las sentencias de los tribunales $a$ $q u o^{8}$, así la incompetencia que ellos invocaban resultaba revocada por el tribunal ad quem. En tanto la consecuencia legislativa constó en la promulgación de Ley 21.018 en junio de 2017, que estableció de forma expresa que los legitimados activos para iniciar un juicio de responsabilidad contractual para hacer efectiva la responsabilidad del empleador en accidentes laborales son tanto el trabajador como sus causahabientes ${ }^{9}$. Ambas consecuencias solucionaron el problema procesal, y consecuentemente permitieron la discusión sustantiva del asunto, esto es, si la acción para reclamar la indemnización de perjuicios de daño moral es o no transmisible.

\section{Las posiciones de la doctrina}

Frente al tópico en cuestión nuestra doctrina no ha sido ajena. Si bien los principales autores que han descrito y dado soluciones a la materia han tenido una clara influencia francesa, ello no les ha impedido alcanzar posiciones que, más allá de interesantes, colisionan entre sí e invitan al jurista a tomar una postura en la problemática. Así, surgen tres hipótesis: aquellos que abogan por la intransmisibilidad de la acción que busca obtener la indemnización del daño

\footnotetext{
${ }^{6}$ La discusión jurisprudencial sobre la transmisibilidad del daño moral se puede vislumbrar en material penal: Corte de Apelaciones de Concepción, Rol № 4825-03, de 26 de abril de 2006; Corte Suprema, Rol № 21614-17, de 22 de mayo de 2018 . Y en sede civil: Corte Suprema, Rol № 309-06, de 27 de junio de 2007; Corte Suprema, Rol № 6196-06, de 27 de noviembre de 2007; Corte de Apelaciones de Santiago, Rol № 1910-11, de 8 de noviembre de 2011, Corte Suprema, Rol № 27842-17, de 1 de marzo de 2018.

${ }^{7}$ Sobre jurisprudencia confirmando la incompetencia de los tribunales laborales en demandas ejercidas vía iure propio véase: Corte Suprema, Rol № 4859-02, de 19 de agosto de 2003; Corte de Apelaciones de Concepción, Rol № 1729-03, de 30 de septiembre de 2003; Corte Suprema, Rol № 3337-08, de 20 de agosto de 2008. Más sobre el argumento en DOMínGUEZ (2002) pp. $259-265$.

${ }^{8}$ Sobre jurisprudencia revocando incompetencia de los tribunales laborales en demandas ejercidas vía iure hereditatis véase: Corte de Apelaciones de Concepción, Rol № 14-2015, de 30 de marzo de 2015; Corte de Apelaciones de La Serena, Rol № 16-2016, de 21 de abril de 2016.

${ }^{9}$ La solución del problema mediante la vía legislativa resultó llegar tarde, pues la alternativa judicial hacia 2017 ya se había logrado. Por ello resulta lógico que en la discusión legislativa la Corte Suprema haya informado desfavorablemente el proyecto de ley mediante el oficio 77-2012, donde en síntesis le indica a la Comisión de trabajo y previsión social lo innecesario de la modificación.
} 
moral; los que plantean una transmisibilidad atenuada de la acción; como también los que sugieren una transmisibilidad absoluta.

\section{Por la intransmisibilidad de la acción}

Dentro de quienes niegan la transmisibilidad de la acción para solicitar una indemnización de perjuicios producto del daño moral se encuentra el Doctor en derecho Ramón Domínguez Águila. En orden a fundamentar su tesis, él se pregunta por la naturaleza del derecho. Así, se refiere por una parte al concepto de daño moral, y por otra, a la finalidad de la institución.

En cuanto al concepto de daño moral, Domínguez Águila señala que una correcta concepción de aquel sería aquella que lo comprende como una lesión a derechos subjetivos o bienes de la personalidad, en oposición a quienes que lo confunden con el dolor, la aflicción o el pesar ${ }^{10}$. Pues esto último correspondería más bien a las consecuencias del daño moral experimentado. De este modo, sufrir un daño moral se traduciría, por ejemplo, en una afectación de la integridad psíquica y física garantizada por la Constitución. Ahora bien, dado que dichos derechos subjetivos o bienes de la personalidad están esencialmente unidos a su titular dejan de existir cuando este fallece, ergo son intransmisibles. Así, el daño moral desaparecería con su titular toda vez que el principio de continuación no implicaría transferir los atributos de la personalidad.

Frente a esta posición existe un contrargumento consistente en distinguir el daño moral de la acción para reclamar su reparación. Pues es innegable que los bienes de la personalidad son intransmisibles, sin embargo, esto no implica consecuentemente que la acción que nace cuando ellos son lesionados también lo sea. Máxime, cuando esta última tiene un evidente contenido pecuniario. Luego, el carácter personal e intransmisible se le imprime al daño moral, no así a la acción indemnizatoria. Ante este planteamiento, el autor se defiende señalando que el interés protegido por la acción no es económico, sino que personalísimo, en sus palabras: "Si el resultado de la acción reparatoria es la obtención de una suma de dinero, ello no hace desaparecer la circunstancia que el interés protegido con la acción es el derecho o la situación jurídica no patrimonial y personalísima que ha sido afectada por el hecho del demandado"11.

En cuanto a la finalidad de la indemnización por daño moral, Domínguez Águila plantea que cumple un rol radicalmente distinto al del daño patrimonial ${ }^{12}$. A saber, la indemnización en casos de daños patrimoniales cumpliría un objetivo de sustitución del bien o interés dañado; mas, cuando se trata de daños extrapatrimoniales - por ejemplo, la honra - la indemnización no podría venir a sustituir aquel bien o interés dañado, pues aquellos bienes no tienen una traducción dineraria, sino que su fundamento se encontraría en la idea de otorgar satisfacciones alternativas a la víctima que logren compensar la pérdida sufrida. Luego, de entregar aquella indemnización al heredero entonces no se cumpliría algún fin reparatorio, sino un enriquecimiento sin justificación alguna. En el mismo sentido se pronuncia Barros, señala que la función de la indemnización de daños no patrimoniales es compensatoria, es decir, "la víctima recibe una indemnización que no pretende restablecer el estado de cosas anterior al daño, sino cumplir la función más modesta de permitirle ciertas ventajas, que satisfagan su pretensión legítima de justicia y la compensen por el mal recibido" ${ }^{13}$.

Con respecto a la jurisprudencia, las Cortes fueron casi uniformes en reconocer el carácter intransmisible de la acción hasta $2016^{14}$, pues en diciembre de dicho año Carlos Pizarro, abogado integrante de la Corte Suprema, redacta el fallo de "Quezada con Colmenares Werner" que

\footnotetext{
${ }^{10}$ DOMÍNGUEZ (2004), p. 503.

${ }^{11}$ DOMÍNGUEZ (2004), p. 504

12 DOMÍNGUEZ (2004), pp. 508-513.

${ }^{13}$ BARROS (2006), p. 302.

${ }^{14}$ Véase Corte Suprema, Rol № 309-06, de 27 de junio de 2007; Corte Suprema, Rol № 6196-06, de 26 de noviembre de 2007; Corte de Apelaciones de Concepción, Rol № 423-07, de 12 de diciembre de 2007; Corte Suprema, Rol № 2073-09, de 29 de septiembre de 2011; Corte de Apelaciones de Santiago, Rol № 1910-11, de 8 de noviembre de 2011; Corte de Apelaciones de San Miguel, Rol № 15206-15, de 4 de mayo de 2016.
} 
cambió radicalmente el paradigma. No obstante, previo a dicho hito, la tendencia era la intransmisibilidad. En efecto, la Corte Suprema en 2007 se hace cargo de los dos planteamientos de Domínguez Águila. Por una parte, indica que existe un vínculo indesmentible y estrecho entre la acción y el daño, pues la primera se justifica en el segundo, lo cual le imprimiría inmediatamente un carácter personalísimo; por otra parte, indica que por más que la acción de lugar a un crédito en dinero (es decir, integre un carácter patrimonial), el contenido de ella seguirá siendo personal, puesto que su finalidad es compensar el mal soportado por la propia víctima que padeció el dolor, la molestia o aflicción en sus sentimientos o facultades espirituales, que en ningún caso se cumpliría entregando la indemnización a sus herederos ${ }^{15}$.

\section{Por la transmisibilidad de la acción}

Cuando se trata de argumentar a favor de la transmisibilidad de la acción en cuestión se deben distinguir dos situaciones. Por una parte, aquella en la que la víctima fallece instantáneamente como consecuencia del hecho productor del daño, por ejemplo, aquel trabajador que muere tras el desastroso desenlace de explosivos con alto poder destructivo ${ }^{16}$; por otra, aquella situación en que ha existido un lapso de tiempo entre la ocurrencia del hecho fatal y la muerte propiamente tal, por ejemplo, el trabajador que por negligencia de su empleador contrajo el virus hanta y fallece semanas después como consecuencia de aquello ${ }^{17}$.

Con esto presente, la tesis de la transmisibilidad absoluta plantea que la acción para perseguir la indemnización del daño moral se incorporaría al patrimonio del causante como cualquier otro crédito, incluso cuando la muerte es instantánea, es decir, con independencia de si existió si quiera un instante de sobrevivencia al hecho productor del daño. Luego, la acción se transmitiría a sus herederos desde que ellos son los continuadores del difunto en todos sus derechos y obligaciones. Para Pablo Rodríguez Grez, que aboga por esta tesis, la distinción planteada anteriormente no sería relevante. En sus palabras "no cabe duda que quien culpablemente priva de la vida a otra persona, está obligado a reparar este perjuicio, así se trate de la mal llamada muerte instantánea" 18 .

El profesor fundamenta su posición en diez razones. Dentro de ellas destacamos dos que podrían sintetizar su argumentación: una, es que el principio de la reparación integral no podría en ningún caso dejar de tutelar el derecho a la vida, pues este tiene expreso reconocimiento en la constitución, además de tener el carácter de fundamental sin el cual todos los demás derechos se diluyen; otra razón, es aquella por la cual señala que no existen las muertes instantáneas, pues "aun cuando exista una fracción mínima de tiempo, el hecho fue anterior a su consecuencia y el difunto alcanzó a adquirir el derecho a ser indemnizado"19. En el mismo sentido se pronuncia el chileno Bidart pues, es su opinión, no se estaría demandando la reparación por un muerto, sino el resarcimiento de una persona que vive, por el hecho de su muerte ${ }^{20}$.

En la doctrina comparada también se encuentran pronunciamientos por la transmisibilidad absoluta de la acción. En Francia, los hermanos Mazeaud sostienen que, de no considerar esta postura, entonces el responsable de un daño que causó la muerte de una persona recibiría un mejor trato por el ordenamiento jurídico que el autor de meras lesiones, pues si la víctima muere en el acto entonces se desvanece la acción de los herederos ${ }^{21}$. Mientras que, en España, Bosch se pronuncia señalando que por más que la muerte haya sido instantánea esta "se imputa a la vida del muerto y no al hecho de la muerte en sí misma (...) por lo que siempre es posible la adquisición por el patrimonio de la víctima del derecho al resarcimiento" 22.

\footnotetext{
${ }^{15}$ Corte Suprema, Rol № 309-06, de 27 de junio de 2007.

${ }^{16}$ Véase Primer Juzgado de Letras del Trabajo de Santiago, Rit № 0-93-2018, de 22 de marzo de 2019.

${ }_{17}$ Véase Segundo Juzgado de Letras de Buin, Rit № O-37-2015, de 4 de mayo de 2016.

18 RODRÍGUEZ (1999), p. 366

${ }^{19}$ RODRÍGUEZ (1999), pp. 366-368.

${ }^{20}$ BIDART (1985), pp. 87 y ss.

${ }^{21}$ MAZEAUD et al. (1962), pp. 540 y ss.

${ }^{22} \mathrm{BOSCH}(1975)$, pp. 665 y ss.
} 
En cuanto a la jurisprudencia, como se mencionó, las sentencias de los altos tribunales de nuestro país reconocieron el carácter intransmisible de la acción hasta diciembre de $2016^{23}$. A pesar de esto, es posible verificar alguna jurisprudencia en aras de la transmisibilidad absoluta de la acción previo a dicha fecha ${ }^{24}$. En este sentido resulta interesante la prevención que realiza el ministro Muñoz en sentencia de la Corte Suprema sobre un juicio de accidente del trabajo en septiembre de 2016. En ella la Corte comienza su razonamiento distinguiendo el daño moral de la acción para reclamarlo. Así, hace presente que, si bien coincide con la jurisprudencia mayoritaria en orden a atribuirle el carácter de personal al daño moral, no considera que el mismo carácter le sea atribuible a la acción indemnizatoria que busca compensar ese perjuicio, pues ella tiene una significación pecuniaria. Continúa abogando por la transmisibilidad de la acción, pues señala que la única forma de sostener que aquella es intransmisible sería mediante una ley, dado al principio transversal del derecho privado por el que está permitido todo lo que no está expresamente prohibido ${ }^{25}$. En lo que importa a este acápite, el ministro finaliza afirmando la transmisibilidad absoluta, pues argumenta que atentaría contra la legalidad el hecho de imponer exigencias, presupuestos o requisitos de hecho a la acción, como haber requerido conciencia o conocimiento del hecho generador de la muerte; o bien, exigir prolongación en el tiempo de estos mismos, como haber sobrevivido por un tiempo más o menos largo que suponga algún tipo sufrimiento para el trabajador. Esto, toda vez que el legislador no ha establecido exigencias fácticas respecto de la generación del derecho ${ }^{26}$. Así, la Corte se aleja la tesis de la intransmisibilidad que la caracterizaba, y aporta un precedente para lo que serán los futuros razonamientos en materia laboral.

En otro orden de ideas, la tesis de la transmisibilidad relativa de la acción pondrá énfasis en la distinción planteada al inicio de este acápite. En consecuencia, señala que cuando la muerte es coetánea al hecho dañoso entonces la acción para reclamar la indemnización de perjuicios por daño moral no habría alcanzado a nacer a la vida del derecho, toda vez que no se habría verificado un daño - pues este requeriría conciencia de aquel hecho, o bien, mantención de las facultades sensitivas-. En cambio, cuando la muerte se verifica mediando un lapso de tiempo entre el hecho dañoso y el deceso propiamente tal, entonces -en la medida que se logre acreditar el daño por haber existido conciencia o facultades sensitivas- la acción en cuestión nacería a la vida del derecho, se incorporaría al patrimonio del causante, y como cualquier otro crédito se transmitiría a sus herederos.

A favor de esta posición, en la doctrina nacional tradicional, se encuentra al profesor Arturo Alessandri y a la profesora Carmen Domínguez Hidalgo. Si bien ambos llegan a la misma solución, se basan en argumentos distintos. Por una parte, Alessandri comienza recordando que el derecho a demandar perjuicios es transmisible, pues ninguna ley ha declarado su carácter contrario. Sin embargo, no siempre los herederos pueden ejercitar tal acción, sino solo cuando la víctima sobrevive al accidente -al menos por breves instantes-, pues en aquel caso la acción habría alcanzado a formar parte de su patrimonio heredable. Concluye que a los herederos le corresponderían dos acciones: aquella que es propia de la víctima directa en la medida que no la hubiera renunciado; y la que les corresponde personalmente por el daño moral que la muerte de la víctima directa les ha irrogado en su propio patrimonio o sentimientos ${ }^{27}$.

Por otra parte, la profesora Carmen Domínguez Hidalgo sostiene la transmisibilidad relativa luego de una interesante argumentación. Comienza por señalar que no habría razones en un plano estrictamente jurídico para declarar el carácter intransmisible de la acción, sin embargo, en un ángulo ético parecería dudosa tal determinación, pues - por ejemplo- causaría desaprobación el que una persona pueda obtener un provecho pecuniario del sufrimiento ajeno.

\footnotetext{
${ }^{23}$ Ver №14.

${ }^{24}$ Véase: Corte de Apelaciones de Santiago, Rol № 3591-00, de 23 de mayo de 2001; y Corte Suprema, Rol № 15206-15, de 26 de septiembre de 2016.

${ }^{25}$ En Corte Suprema, Rol № 15206-15, de 26 de septiembre de 2016, considerando onceavo de prevención.

${ }^{26}$ En Corte Suprema, Rol № 15206-15, de 26 de septiembre de 2016, considerando doceavo de prevención.

${ }^{27}$ ALESSANDRI (1943), pp. 467-473.
} 
A pesar de este razonamiento ético, adopta una decisión de técnica jurídica al declarar que siguiendo los principios sucesorales se debería concluir la transmisibilidad de la acción, pero destaca que en ningún caso adheriría a la idea de la transmisibilidad absoluta, pues implicaría concebir la indemnización como pena, y un enriquecimiento sin justificación ${ }^{28}$. En el mismo sentido se pronuncia Hernán Corral Talciani, luego de razonar sobre los argumentos de la autora ${ }^{29}$.

Tanto Alessandri como Domínguez Hidalgo comienzan su razonamiento con la premisa de que no hay razones normativas para considerar a la acción de indemnización de perjuicios por daño moral dentro de aquellos derechos con el carácter de personalísimos, luego intransmisibles. De allí que Díaz se pregunta cuáles son los criterios que le han servido de base al legislador para calificar una situación jurídica como tal, pues si la acción para reclamar el daño moral se subsume en uno de estos criterios entonces ella se podría considerar como intransmisible. La autora determina que existen tres criterios: un criterio económico, por ejemplo, para el fideicomiso, derecho de usufructo, uso y habitación; un criterio de orden público, por ejemplo, en el derecho de alimentos; y un criterio de confianza, como en el albaceazgo y el contrato de mandato. Luego, concluye que no solo el legislador omitió atribuirle el carácter personalísimo a la acción en cuestión, sino que tampoco se podría concluir tal carácter, pues no habría razones económicas, de orden público, o bien de confianza para determinarlo ${ }^{30}$.

Hacia el derecho comparado, podemos afirmar que la generalidad de los ordenamientos jurídicos europeos que adhieren a la tesis de la transmisibilidad consideran su acepción relativa. Así, en Grecia, los tribunales han rechazado la indemnización en consideraciones a la falta de conciencia de la víctima cuando el hecho dañoso es simultaneo a la muerte; en Inglaterra e Italia, se exige un período de tiempo razonable entre el momento del accidente y el de la muerte; mientras que en Bélgica, se requiere que la víctima hubiese sido consciente del daño ${ }^{31}$.

En cuanto a la jurisprudencia nacional los tribunales laborales se han mostrado firmes en declarar la transmisibilidad relativa de la acción desde diciembre de $2016^{32}$. Ya sea realizando una argumentación fundada, o bien, citando la sentencia "Quezada con Colmenares Werner". En ambos casos el razonamiento es el mismo, y los tribunales tienden a descartar la transmisibilidad absoluta de forma más o menos expresa.

A saber, dicha sentencia consistió en una acción de indemnización de perjuicios derivado de un accidente del trabajo, la cual fue interpuesta por la cónyuge del trabajador fallecido en conjunto con sus hijos. Los fundamentos de la demanda dicen relación con que el causante habría fallecido luego de haber contraído el virus hanta en las dependencias de su empleador, toda vez que este último no habría cumplido con su deber de seguridad para prevenir que sus trabajadores se contagien. Frente a ello, Corte resuelve en base al carácter pecuniario de la acción. Es decir, entiende que una vez verificado el daño moral nacería una acción para reclamar su indemnización, y al ser esta indemnización traducible en dinero entonces a la acción se le impregnaría un carácter patrimonial. Una vez que posee este carácter, entonces cabría calificarla como un bien mueble, luego se transmitiría a los herederos del causante como cualquier otro bien del cujus $^{33}$. Enseguida, se hace cargo de la transmisibilidad absoluta señalando:

\footnotetext{
28 DOMÍNGUEZ (2000), pp. 728-736.

${ }^{29}$ CORRAL (2004), pp. 320-321.

${ }^{30}$ DÍAZ (2017), pp. 103-114.

${ }^{31}$ BARRIENTOS (2005), p. 15

32 Véase Juzgado de Letras y Garantía de Paillaco, Rit № 0-2-2017, de 8 de junio de 2017; Juzgado de Letras del Trabajo de Curicó, Rit № 0-132-2017, de 20 de noviembre de 2017; Juzgado de Letras del Trabajo de San Felipe, Rit № 0-176-2017, de 9 de febrero de 2018; Primer Juzgado de Letras del Trabajo de Santiago, Rit № 0-2629-2017, de 20 de febrero de 2018; Primer Juzgado de Letras de Los Andes, Rit № 0-88-2017, de 10 de abril de 2018; Juzgado de Letras del Trabajo de Punta Arenas, Rit № 0-148-2017, de 29 de junio de 2018; Primer Juzgado de Letras del Trabajo de Santiago, Rit № O-1873-2018, de 3 de diciembre de 2018; Juzgado de Letras de La Calera, Rit № O-44-2018, de 28 de diciembre de 2018; y Primer Juzgado de Letras del Trabajo de Santiago, Rit № O-93-2018, de 22 de marzo de 2019.

${ }^{33}$ En Corte Suprema, Rol № 33990-16, de 27 de diciembre de 2016, considerando quinto.
} 
la víctima directa no falleció en forma instantánea o de manera coetánea al accidente, sino que transcurrió un lapso (...) Debe, en consecuencia, tenerse por un hecho que la víctima sobrevivió al accidente o acto negligente, lo que importa el ingreso de la acción a su patrimonio, y habilitaría a transmitirla a sus herederos ${ }^{34}$

de allí que se puede inferir, a contrario sensu, que de haber muerto el trabajador de forma instantánea producto del accidente del trabajo entonces la acción no habría ingresado a su patrimonio. En efecto, es lo que recientemente han entendido los jueces de letras del trabajo ${ }^{35}$. Por ejemplo, el 22 de marzo de 2019, el primer Juzgado de Letras del Trabajo de Santiago, al conocer de una causa de accidente laboral en que el trabajador tuvo una muerte inmediata producto de una explosión, señaló que

el trabajador no habría alcanzado a sufrir física o psíquicamente alguna fracción de tiempo entre el accidente y la muerte que le siguió, no habría alcanzado a experimentar un sufrimiento que diera lugar a una acción de indemnización que con su posterior muerte se pudiera transmitir a sus herederos ${ }^{36}$.

Desde luego, lo que diferenciaría acogerse a la tesis de la transmisibilidad absoluta o relativa no es más que la concepción objetiva o subjetiva que se tiene del daño moral. Aquellos que consideran el daño moral como la privación de derechos de la personalidad -como la vida-, entonces se inclinarán por la tesis absoluta, pues la muerte sería un daño en sí mismo para el causante. En cambio, para aquellos que el daño moral se asemeja -en términos generales - al sufrimiento de la víctima, entonces seguirán la tesis relativa ${ }^{37}$, y en consecuencia, para obtener la indemnización de perjuicios deberán probar el daño que medió entre el acaecimiento del hecho fatal y la muerte.

\section{Ante un caso difícil o dudoso}

Teniendo las distintas posiciones doctrinarias en mente, el escenario académico describe un debate sobre el verdadero alcance de la ley con respecto a la posibilidad de la transmisión de la acción en discusión. Los preceptos que dan lugar a las dos grandes interpretaciones posibles son los artículos 951 y 1097 del Código Civil, pues con respecto a la transmisión de las acciones indemnizatorias por daños patrimoniales, como el daño emergente o el lucro cesante, el sentido del artículo 2315 es claro a declararlas transmisibles ${ }^{38}$. Ahora bien, los artículos 951 y 1097 del Código declaran que los herederos representan a la persona del difunto y le suceden en todos sus derechos y obligaciones transmisibles, y es justamente aquí donde las reglas de interpretación civiles no llegan a responder qué sucede con la acción para reclamar la indemnización de perjuicios por daño moral sufrido por el causante ¿Esta ella dentro de aquellos derechos transmisibles?

Algunos en consideración a que el legislador estableció expresamente la intransmisibilidad de ciertos derechos - como el usufructo, uso y habitación-, consideran que la regla general en el ordenamiento sería la transmisibilidad, por lo que la acción del daño moral se subsumiría en la hipótesis normativa de los artículos, ergo sería transmisible. Mientras que, para otros, la hipótesis no alcanzaría a la acción en comento pues ella estaría intrínsecamente unida al daño moral, y dado que este afecta a bienes de la personalidad naturalmente intransmisibles entonces dicho carácter se le imprimiría a la acción indemnizatoria.

Cabe tener presente que el legislador no se pudo haber planteado la situación sobre si dicha acción se subsumiría o no en la hipótesis de los artículos en discusión toda vez que a la

\footnotetext{
${ }^{34}$ Corte Suprema, Rol № 33990-16, de 27 de diciembre de 2016.

${ }^{35}$ Ver №32.

36 Primer Juzgado de Letras del Trabajo de Santiago, Rit № O-93-2018, de 22 de marzo de 2019.

${ }^{37}$ DOMÍNGUEZ (2000), pp. 733-734.

38 DOMÍNGUEZ (2000), p. 732; y BARROS (2006), p. 943.
} 
época de dictación del Código los daños extrapatrimoniales no se consideraban susceptibles de reparación. Por lo tanto, es imposible encontrar una solución acudiendo a la historia de la ley. Tampoco se encuentra una solución normativa expresa en algún cuerpo legal especializado. Con respecto a ello, algunos podrían argumentar que en virtud del artículo 88 de la Ley de Accidentes del Trabajo y Enfermedades Profesionales (Ley 16.744) la acción en cuestión tendría el carácter de intransmisible, ya que dicho precepto declara que los derechos conferidos por la mencionada ley son personalísimos, en circunstancias que reconoce expresamente la reparación del daño moral. Sin embargo, sería incorrecto concluir que el artículo alcanza a las acciones indemnizatorias, pues ello implicaría que las acciones para resarcir el daño emergente y el lucro cesante no serían transmisibles, lo cual es contradictorio al artículo 2315 del Código Civil. Así lo ha entendido la jurisprudencia, señalando que en realidad el artículo 88 de la Ley "alude a aquellos [derechos] de índole social, en particular a las prestaciones médicas, por incapacidad, invalidez, y por supervivencia" ${ }^{39}$. Es por ello que se afirma que las reglas de interpretación civiles no alcanzan a dirimir la cuestión en debate.

Ahora bien, lo dudoso de este caso se ve acentuado y reafirmado cuando se traslada a al plano jurisprudencial. En este sentido, si bien la sentencia de la Corte Suprema en la causa caratulada "Quezada con Colmenares Werner", de diciembre de 2016, pretendió terminar con la discusión que existió entre las hipótesis planteadas y sentar un precedente en aras de la transmisibilidad de la acción, tal solución no fue más que aparente. Así, menos de dos años bastaron para que el excelentísimo tribunal cambiara su criterio interpretativo y considerara la acción en cuestión intransmisible. En mayo de 2018, resolviendo sobre un juicio de crímenes de lesa humanidad ocurridos en Colonia Dignidad, la Suprema señaló que

\begin{abstract}
en cuanto a la transmisión de la acción por el daño moral sufrido por el causante, esta Corte ha sostenido que ella tiene un carácter personalísimo, toda vez que persigue compensar el mal soportado por la víctima personalmente y que la circunstancia de existir un vínculo entre la acción y el resarcimiento pretendido - que es de carácter pecuniario - no obsta a la antedicha conclusión, por cuanto el resarcimiento se genera y justifica en la aflicción de la víctima, lo que le confiere el carácter de personalísimo ${ }^{40}$.
\end{abstract}

Si bien el citado fallo es producto de un recurso de casación en la forma y fondo en materia penal, a diferencia del recurso de unificación de jurisprudencia en materia de laboral, no resta a la conclusión de que aún la Corte Suprema duda sobre el caso en cuestión, lo que le impide uniformar su razonamiento.

De este modo se arriba a la conclusión de que existe un caso difícil o dudoso, ya sea por la imposibilidad de aplicar el método deductivo o la subsunción jurídica en su solución ${ }^{41}$, o bien porque el caso "es de tal modo novedoso o imprevisible que se estima que no hay regla que le sea aplicable" 42 . Ello en razón de lo difícil de subsumir la hipótesis a los artículos 951 y 1097 del Código Civil, además de la carencia de una norma expresa, lo que ha llevado a diversas tesis doctrinarias y repentinas vacilaciones de la Corte Suprema sobre la transmisibilidad de la acción indemnizatoria del daño moral. Lo anterior es peligroso a la luz del principio de la certeza jurídica, pues cuando el excelentísimo tribunal resuelve en aras de determinada posición, se crea una legítima expectativa en el jurista consistente en que el razonamiento se seguirá sosteniendo en el futuro en la medida que las circunstancias sigan siendo las mismas. Lo anterior, sin ánimos de atentar contra el efecto relativo de las sentencias, no es más que la demostración práctica dicho principio, el cual se ve vulnerado cuando ante la misma hipótesis se falla de modos contradictorios entre sí.

\footnotetext{
${ }^{39}$ Corte Suprema, Rol № 33990-16, de 27 de diciembre de 2016.

${ }^{40}$ Corte Suprema, Rol № 21614-17, de 22 de mayo de 2018.

${ }^{41}$ STREETER (1993), pp. 210-211.

42 BARROS (1984), p. 276.
} 
Lamentablemente, no parece ser novedoso que la Corte Suprema cambie sus razonamientos en materia laboral cuando está ante casos difíciles o dudosos. Por ejemplo, sobre la posibilidad de aplicar la regla de suspensión de la caducidad de la acción por despido injustificado a los casos de autodespido o despido indirecto, el Código del Trabajo no ofrece una solución expresa en artículo 171 que regula este último. Así, estando ante un caso de duda, el excelentísimo tribunal fallando sobre un recurso de unificación de jurisprudencia en la materia, declaró que la regla de suspensión del artículo 168 también se aplica los casos de autodespido del artículo 171 del Código del Trabajo. Sin embargo, dicha posición no se siguió manteniendo con posterioridad ${ }^{43}$.

Es entonces que cabe preguntarse si es que existe alguna razón, más allá de los argumentos civilistas tradicionales, para declarar la transmisibilidad de la acción en materia laboral. Pues solo en la medida que aquella exista, entonces el razonamiento de la Corte Suprema se vería fortalecido, lo que evitaría un posible cambio de criterio en la materia. Palavecino trata de encontrar una razón de fondo haciendo - en sus palabras - un psicoanálisis del juicio "Quezada con Colmenares Werner". Así, opina que la Corte Suprema quiso resolver un problema social "porque en la mente de los sentenciadores está la imagen potente, apremiante, de la joven viuda y los pequeños huérfanos y, en ese imaginario, la reparación cobra un carácter prácticamente alimentario" ${ }^{44}$. Sin embargo, el presente estudio busca otorgar una respuesta que va más allá del caso concreto al que alude Palavecino, se pretenderá dar una solución a la problemática en aras de la certeza jurídica al tomar en cuenta el principio protector que informa al Derecho Laboral, el cual se ve opacado por los argumentos evidentemente civiles de los tribunales, y dogmáticos del Derecho.

\section{El principio protector}

Cuando se está ante un caso difícil o dudoso, en el que es cuestionable el alcance de las normas sobre las que se puede subsumir, es legítimo recurrir a los principios del derecho para encontrar una solución. Barros, en apoyo a esta alternativa, indica que ya en los casos que generan dudas sale a luz la importancia regulativa de los principios, pues dado que las reglas cambian con mayor facilidad que estos últimos, entonces en ellos se encontraría mayor certeza ${ }^{45}$. Así, en tanto la discusión del carácter transmisible de la acción indemnizatoria del daño moral se da principalmente en materia laboral, entonces se buscará una solución mirando a los principios que inspiran esta rama del derecho.

El principio protector es el que naturalmente orienta al derecho del trabajo. Esto se ve tanto en su fase legislativa, es decir, al crear derecho; como en su etapa judicial, al interpretar el derecho. Este principio encuentra como fundamento la falta de libertad del trabajador al momento de contratar, pues para él el trabajo es una necesidad ${ }^{46}$. Plá encuentra también un fundamento del mismo en las distintas formas de explotación que se producían producto de la desigualdad de poder entre las partes de la relación laboral. En este sentido, el legislador no habría podido continuar con el imaginario de un plano de igualdad entre las partes del contrato de trabajo, y -al igual que lo que ocurre en el derecho del consumidor - tendió a compensar la desigualdad con una protección jurídico-legislativa favorable hacia la parte más débil de la relación: el trabajador ${ }^{47}$.

Si bien hay autores que argumentan que el principio ha ido decayendo en el último tiempo ${ }^{48}$, dicha realidad se escapa del escenario chileno. Es innegable que en otras jurisdicciones la explotación y desigualdad de poder en las relaciones laborales ha tendido a disminuir gracias

\footnotetext{
43 SILVA (2019), pp. 436-438.

${ }^{44}$ PALAVECINO (2018), pp.124-126.

45 BARROS (1984), p. 276.

${ }^{46}$ GAMONAL (2014), p. 154.

${ }^{47}$ PLÁ (2015), pp. 74-78.

${ }^{48}$ MUNITA (2014), pp. 85 y 86.
} 
a diversos factores. Dentro de ellos el rol de los sindicatos, y la mayor conciencia sobre la dignidad y derechos de los trabajadores. Esto ha tenido el efecto de que, por ejemplo, en países como Alemania, España, Francia e Italia el principio protector no tenga cabida en la interpretación de normas laborales ${ }^{49}$. Sin embargo, resulta difícil argumentar la misma realidad y su consecuencia en nuestro país ${ }^{50}$, lo que impide una relajación del principio protector. Así, la Corte Suprema continúa usando el principio en la fundamentación de sus sentencias ${ }^{51}$. Incluso se argumenta por Gamonal que en Latinoamérica "el principio de protección es un pilar del derecho del trabajo" 52 , el que hace que la doctrina laboral sea más protectora que en otras jurisdicciones ${ }^{53}$.

Es menester destacar que el reconocimiento de este principio subsiste en todo el Código del Trabajo (CT). En este sentido, hay diversas normas con un claro carácter protector: la presunción de existencia del contrato de trabajo, los límites a la jornada de trabajo, el sistema causado de despido, los descansos irrenunciables, entre otros, que no son más que demostraciones de cómo este principio informa el ordenamiento laboral. Incluso Gamonal señala que este principio tiene un reconocimiento constitucional en Chile, a saber, en el artículo 19 №16 al otorgar amparo a la libertad de trabajo y su protección ${ }^{54}$.

Siguiendo a Plá, el principio en comento se expresa en tres formas diferentes ${ }^{55}$. A saber, la regla in dubio pro operario, la regla de la norma más favorable, y la regla de la condición más beneficiosa. La doctrina señala como manifestación fundamental del principio la primera de estas reglas ${ }^{56}$, la que se tratará a continuación en orden a responder el porqué en materia laboral se debería continuar con el criterio de la transmisibilidad.

\section{Regla In Dubio Pro Operario}

La regla in dubio pro operario ordena que ante un caso de duda se resuelva a favor del trabajador. Algunos autores tienden a restringirlo señalando que se aplica solo cuando una norma se puede entender de dos o más sentidos distintos. Así, Plá lo define como el criterio según el cual "si una norma puede entenderse de varias maneras, debe preferirse aquella interpretación más favorable al trabajador" 57 . Mientras que Ackerman considera que "cuando una norma laboral admita más de una interpretación, el intérprete debe optar por aquella que resulte más favorable para el trabajador" ${ }^{\prime 58}$. Sin embargo, la jurisprudencia al aplicarlo lo ha entendido con una mayor extensión. Así, la Corte no lo restringe a normas, sino que a casos dudosos: "en casos dudosos o difíciles que no son posibles de dilucidar con los métodos tradicionales o que conduzcan a resultados injustos, ha de optarse por la interpretación que más favorezca al trabajador" 59 . Lo cual va en congruencia a como lo entiende Gamonal, quien señala que la principal aplicación de la regla "se presenta frente a los casos difíciles o dudosos"60.

La estructura de esta regla se encuentra también en otras ramas del ordenamiento jurídico. Por ejemplo, en el derecho penal se formula como in dubio pro reo, y ordena que ante un caso de duda se prefiera aquella interpretación más favorable para el imputado. Mientras

\footnotetext{
49 MUNITA (2014), p. 93.

50 Por ejemplo, entre los años 2014 y 2016 las denuncias por prácticas antisindicales ascendieron a 4.666. En este último año, frente a la declaración sobre si "En Chile se respeta los derechos de los trabajadores", solo un 14\% de los trabajadores encuestados declaró estar "de acuerdo" o "muy de acuerdo", BALTERA y MUÑOZ (2017), pp. 8 y 107.

51 Por ejemplo, en Corte de Apelaciones de Concepción, Rol № 152-17, de 30 de junio de 2017. Otros en Corte Suprema, Rol № 4317-14, de 12 de abril de 2014; Corte Suprema, Rol № 21966-14, de 2 de octubre de 2014; Corte Suprema, Rol № 10139-13, de 19 de junio de 2014; Corte de Apelaciones de Concepción, Rol № 152-17, de 30 de junio de 2017.

52 GAMONAL (2013), p. 430.

53 GAMONAL (2019), p. 33.

54 GAMONAL (2013), pp. 425-458, y GAMONAL (2014), p. 152

55 PLÁ (2015), p. 91.

${ }^{56}$ ALONSO (1987), p. 287.

57 PLÁ (2015), pp. 84 y 85.

${ }^{58}$ ACKERMAN (2005), p. 339.

${ }^{59}$ Corte de Apelaciones de Concepción, Rol № 152-17, de 30 de junio de 2017.

${ }^{60}$ GAMONAL (2014), p. 160.
} 
que en el derecho civil se encuentra en el artículo 1566 del Código Civil, que dispone que las cláusulas ambiguas del contrato se interpretan a favor del deudor. Así, donde el Código estima como el sujeto débil de la relación al deudor, "para el derecho laboral es el trabajador el débil, sea deudor o acreedor" 61 .

A mayor abundamiento, la regla en cuestión no solo es privativa de la interpretación de la ley. En este sentido, se extiende a la interpretación del contrato de trabajo y sus anexos, así como también al reglamento interno de la empresa. Sin embargo, su aplicación es debatible en el ámbito de los instrumentos colectivos, pues se entiende que dentro de estas negociaciones los sindicatos se relacionan con el empleador a un nivel relativamente más equitativo que cuando lo hacen los trabajadores considerados individualmente ${ }^{62}$.

Ahora bien, con respecto al presente estudio se analizará el rol de la regla hermenéutica en relación a la interpretación de la ley. En este sentido, las condiciones de aplicación de este principio son claras para Plá, Ackerman y Tosca. Por una parte, solo se aplicará cuando exista una duda sobre el alcance de la norma legal; por otra, siempre que no esté en pugna con la voluntad del legislador. A continuación, se analizará si frente a la quaestio jurídica en disputa se dan dichas condiciones para que proceda la aplicación de la regla.

En cuanto a la duda sobre el alcance de la norma legal, se deberá estar a los artículos 1097 y 951 del CC. Aquellos son los preceptos en los que se advierte una falta de certeza en cuanto a si la acción para conseguir la indemnización por daños extrapatrimoniales se subsume o no en la hipótesis de derechos transmisibles. Esta duda generaría entonces un caso difícil pues representa una imposibilidad de aplicar la subsunción jurídica en su solución ${ }^{63}$. Por consecuencia el presente problema causa diversas tesis en la materia y cambios de criterios en la Corte, como declararse a favor de la transmisibilidad en "Quezada con Colmenares Werner", y luego volver a la intransmisibilidad en el juicio de Colonia Dignidad. Luego, como lo ha sostenido la Corte, una vez que se está ante estos casos cabe optar por la interpretación más favorable al trabajador ${ }^{64}$.

Así las cosas, queda hacerse cargo de la segunda condición para la aplicación de la regla in dubio pro operario: que no se esté en pugna con la voluntad del legislador. Como ya se precisó, es de todo conocimiento jurídico que Bello no tuvo en cuenta el daño moral al momento de redactar el Código Civil, sino que su construcción surge a partir del artículo 2329 de dicho cuerpo legal. No conocemos la voluntad original del legislador, ni siquiera existía la noción de daño moral en las obras de la época de dictación del Código. Por lo tanto, se deberá atender a la voluntad actual del legislador la cual no es expresa en cuanto al carácter transmisible de la acción, luego no estaría siendo vulnerada, pues solo la podríamos considerar transgredida en la medida que sea conocida, y justamente tal desconocimiento de la voluntad de la ley es la que nos está llevando a este cuestionamiento.

Una vez verificadas las condiciones de aplicación de la regla in dubio pro operario queda determinar cuál es la interpretación más favorable al trabajador: la tesis de la transmisibilidad o la intransmisibilidad.

En primer lugar, considerar la tesis de la intransmisibilidad implicaría dejar de reparar los daños extrapatrimoniales que se le causaron al trabajador cuando por negligencia de su empleador se le privó de su vida. De este modo, el empleador que no da cumplimiento al deber de seguridad, que por su negligencia causa la muerte al trabajador, quedaría en una posición mucho más beneficiosa que aquel empleador que por su negligencia provocó un accidente del cual no hubo víctimas fatales, en circunstancias que privar del derecho vida será siempre más grave que una mayor o menor vulneración a la integridad física y psíquica.

Así las cosas, siempre será más favorable para el trabajador que el ordenamiento jurídico, y el juez al aplicarlo, otorgue mayor protección a una situación fáctica con peores consecuencias

\footnotetext{
61 GAMONAL y ROSADO (2014), p. 156.

62 GAMONAL Y ROSADO (2014), p. 630.

63 STREETER (1993), pp. 210-211.

${ }^{64}$ Corte de Apelaciones de Concepción, Rol № 152-17, de 30 de junio de 2017.
} 
que otra. Por una parte, resulta contradictorio abogar por el amparo de una situación, mas declarar extinta su protección cuando la misma se agrava. Por otra parte, al adoptar la interpretación a favor de la transmisibilidad, el trabajador tendría la seguridad de que si un accidente fatal le llega a suceder por negligencia de su empleador, su patrimonio hereditario se vería incrementado. Lo cual es de todo su interés cuando se tiene presente la función social del trabajo, donde no tan solo se debe mirar al trabajador como un ente independiente, sino como un sostenedor familiar: él no tan solo vela por sí, también por quienes de él dependen. Dicha función social está reconocida en el artículo 2 del Código del Trabajo, como también en distintas normas que velan por sus relaciones familiares ${ }^{65}$.

En segundo lugar, el hecho de adherir a tal interpretación implica un honorable reconocimiento de la voluntad - en potencia- que tiene el trabajador más allá de su muerte, de poner en movimiento el aparato jurisdiccional para haber obtenido una reparación de su daño. Lo cual es del todo conforme con el reconocimiento que hace el ordenamiento jurídico de la transmisibilidad de las acciones indemnizatorias derivadas del daño a las cosas (en el artículo 2315 del Código Civil).

A pesar de que por los comentados motivos la decisión de acogerse a la tesis de la transmisibilidad de la acción responde a aquello que resulta más favorable para el trabajador, hay quienes lo continuarán negando con fundamento en el concepto de daño moral y la finalidad de la indemnización. Lo primero se refuta haciendo la correcta separación entre daño y acción que ha realizado la Corte últimamente dado el evidente carácter pecuniario de la última. Quienes plantean lo segundo, argumentan que el telos de la acción indemnizatoria de los daños extrapatrimoniales en ningún caso se cumpliría cuando su titular ha fallecido. Domínguez Águila recuerda que la finalidad de indemnizar los daños patrimoniales no es otra que otorgar un sustituto del bien o interés dañado, sin embargo, cuando se trata del daño moral la reparación sería simbólica de aquellos perjuicios imposibles de traducir en dinero. Se trataría de una reparación que intenta compensar la pérdida sufrida, y por lo mismo debería recibirse por la víctima directa ${ }^{66}$. El problema de sostener esta argumentación para el escenario de los accidentes de trabajo, es que el deber de seguridad que le compete al empleador - del cual deriva la acción en cuestión- está estrechamente relacionado con la función social del trabajo. Lo anterior bien se explica en la discusión parlamentaria del proyecto de ley que buscó modificar la competencia de los juzgados del trabajo, así la una vez oficiada la Corte Suprema por el Senado, los ministros declararon:

Cuando el artículo 184 del Código del Trabajo obliga al empleador y lo supone responsable por accidentes de trabajo o enfermedades profesionales, está amparando no solamente el trabajador, tanto en su dimensión física como espiritual, sino, al mismo tiempo, la seguridad, en esos respectos, de quienes de él dependen ${ }^{67}$.

En congruencia con lo dicho por la Corte, se sostiene que la finalidad de la indemnización - si bien debe responder a una reparación simbólica - no puede estar desligada de los fines del deber de seguridad, pues solo a este responde. La acción indemnizatoria nacerá una vez verificado un daño moral, que tiene su causa en la acción negligente del empleador por haber incumplido el deber de seguridad al cual se comprometió. Luego, la indemnización por el daño moral sufrido encuentra un fundamento en dicho deber. Así, su fin reparatorio no tan solo puede estar pensado en el trabajador individualmente considerado, sino también en quienes dependen de él, toda vez que como señala la Corte, el deber de seguridad ampara tanto al trabajador como a estos últimos. Por lo tanto, es legítimo sostener que en estos casos la indemnización pueda ser aprovechada por sus herederos.

\footnotetext{
${ }_{65}$ Por ejemplo, la protección a la maternidad, la paternidad y la vida familiar en los artículos 194 y siguientes del Código de Trabajo.

${ }^{66}$ Domínguez (2004), p. 512.

${ }^{67}$ Corte Suprema, oficio № 77-2012, en CONGRESO NACIONAL (2017), p. 8.
} 
De todos modos, algunos podrían argumentar que en aquellos casos en que los herederos buscan una indemnización lo que se debería hacer es accionar vía iure propio en sede civil. Lo cual es correcto, sin embargo, ello no quita que se pueda interponer la respectiva acción en los tribunales del trabajo vía iure hereditatis, pues las indemnizaciones no son incompatibles entre sí. Por un lado, la acción indemnizatoria que se ejerce en sede laboral buscará compensar el daño moral sufrido por el trabajador como víctima directa, que puede ser aprovechado por sus causahabientes toda vez que responde al deber de seguridad que ampara tanto al trabajador como a quienes de él dependen. Por otro lado, la acción indemnizatoria que se ejerce en sede civil persigue la reparación del daño que ciertas personas sufrieron por repercusión o rebote, dado que tenían un especial vínculo afectivo con la víctima. Por lo tanto, una vez que se ejerció la acción en una sede y se pretende ejercer en otra resultaría incorrecto acoger una excepción de litis pendencia, pues no habría identidad de cosa pedida ${ }^{68}$, o ya habiendo terminado uno de los juicios, de cosa juzgada. Incluso, de restringir la posibilidad de acción de los causahabientes exclusivamente a la sede civil, se atentaría contra la voluntad del legislador, toda vez que en la discusión de Ley 21.018, que modificó la competencia de los tribunales laborales, lo que se pretendía era justamente que los herederos del trabajador pudiesen beneficiarse de las ventajas del procedimiento laboral, principalmente la celeridad ${ }^{69}$.

\section{¿Laguna Normativa?}

No obstante el razonamiento anterior, se podría plantear la interrogante sobre si el problema responde a una laguna legal. La profesora Carmen Domínguez Hidalgo es clara al sostener que la cuestión en estudio "no aparece resuelta explícitamente en la ley"70, por lo que no sería curioso que existan opiniones que nieguen la aplicación de la regla in dubio pro operario debido a que no se estaría frente a una duda interpretativa que provoca un caso difícil, sino que ante un caso dudoso, que en palabras de Barros será aquel donde no existe una regla aplicable ${ }^{71}$.

Ante este problema, el juez no se encontraría ante una disyuntiva de interpretación de la ley, sino más bien ante la situación en que por medio del mandato constitucional de la inexcusabilidad él debiese integrar derecho. En este sentido se pronuncia Bulygin, quien reconoce que ante la situación excepcional de lagunas o contradicciones normativas se le abre la posibilidad al juez de crear derecho ${ }^{72}$. El criterio también es compartido con Edicott, quien señala que los jueces ejercen una "función creativa de resolver las dispuestas irresueltas sobre las exigencias del derecho"73. En el mismo sentido surge la teoría de Dworkin, para quien los jueces actúan como colegisladores ${ }^{74}$.

Ahora bien, de adherir a la hipótesis de la existencia de una laguna normativa donde el juez deberá crear derecho, habrá que poner atención al planteamiento de Barros y Gamonal. El primero, vuelve a recomendar el uso de los principios ${ }^{75}$, mientras que el segundo es de la opinión que el juez deberá elaborar una norma siguiendo el criterio pro operario, que no es más que la vertiente judicial integrativa del in dubio pro operario: "el juez frente a una laguna (normativa o axiológica) (...) [crea] una regla específica para el caso concreto"76. De tal modo, en caso de vacío legal, el juez - para proteger al trabajador - fallará creando una norma que declare la transmisibilidad en base a los argumentos esgrimidos precedentemente.

\footnotetext{
${ }^{68}$ CORRAL (2010), p. 37.

${ }^{69}$ CONGRESO NACIONAL (2017), pp. 3-4. El procedimiento laboral, a diferencia del civil, tiene una duración menor, existe una presunción de culpa, y la valoración de la prueba es mediante la sana crítica, sobre el particular revisar BARROS (2006), pp. 694-715. 70 DOMÍNGUEZ (2000), p. 732.

${ }^{71}$ BARROS (1984), p. 276

72 BULYGIN (2003), p. 35.

73 ENDICOTT (2006), p. 289.

${ }^{74}$ DWORKIN (1986), p. 223.

75 BARROS (1984), p. 276

${ }^{76}$ GAMONAL (2014), p. 161.
} 


\section{Conclusión}

La argumentación anterior, en base al principio protector, permite sostener la transmisbilidad de la acción para reclamar la indemnización de los daños extrapatrimoniales en sede laboral, pues es lo que parece más favorable al trabajador. Si bien esta posición es bajo la cual últimamente las Cortes han fallado, los argumentos utilizados no son aquellos aquí esgrimidos, sino que se basan en razones civiles que se sintetizan en la separación intelectual de derecho y acción. En este sentido, se comprende que lo personalísimo es el daño, más no la acción, máxime cuando esta tiene un contenido pecuniario. A pesar de esto, la argumentación continúa siendo débil, pues el caso es de aquellos denominados difíciles o dudosos, por no contener una solución expresa. Así las cosas, la intención plasmada en este estudio resulta de encontrar otros argumentos en la línea puramente laboral a la luz del principio protector, pues solo reforzando los argumentos civiles a la luz de dichos principios se evitará el peligro de un posible cambio de paradigma en la materia. Riesgo que se ve aumentado, toda vez que el escenario actual provocará un auge de las demandas por accidentes del trabajo debido a la inminente falta de diligencia de algunos empleadores en cuanto a la prevención del esparcimiento del COVID-19.

Es menester advertir, que mientras no se otorgue una solución normativa al respecto, entonces se continuará con la incerteza jurídica de enfrentarse a una Corte que fallará dependiendo las posturas que adopte su integración. Frente a esto se propone que se regularice la materia en aras de uniformar el razonamiento independiente la rama legal de la que forme parte. Así entonces se podrán subsanar interrogantes que se escapan al ámbito del estudio de este trabajo: como lo es la posibilidad de cesión de la acción, si es que esta debe considerarse en el inventario de la posesión efectiva en orden a ejercerse, o si debe pagar el impuesto a la herencia como otro bien mueble.

\section{BIBLIOGRAFÍA CITADA}

ACKeRMAN, MARIo (2005): Tratado de Derecho del Trabajo (Buenos Aires, Rubinzal - Culzoni Editores), tomo I.

AleSSANDRI, ARTURo (1943): De la Responsabilidad Extracontractual en el Derecho Civil Chileno (Santiago, Imprenta Universitaria).

Alonso, Manuel (1987): Curso de Derecho del Trabajo (Madrid, Ariel Derecho).

BAltera, PABlo y MuÑOZ, PATRICIO (2017): Prácticas Antisindicales: una dinámica interaccional descolectivizadora (Santiago, Departamento de Estudios de la Dirección del Trabajo).

BARRÍA, MANUEL (2018): “Comentario de sentencia sobre la transmisibilidad del daño moral. Corte Suprema, 27 de diciembre de 2016, Rol 33990-2016, 40 sala", en: Cárdenas, Hugo (Ed.), Jurisprudencia Crítica Comentarios de Fallos 2015-2017 (Santiago, Rubicón Editores) pp. 109117.

BARRIENTOS, MARCELO (2005): "La transmisibilidad de la acción por daño moral en el derecho privado europeo", en: La Semana Jurídica (№ 218), pp. 14-16.

(2007): “Negación de Daños Morales a una Persona Jurídica en materia Contractual", en: Revista Chilena de Derecho (Vol. 34, № 1), pp. 135-138.

(2008): "Del Daño Moral al Daño Extrapatrimonial: La superación del Pretium Dolorios", en: Revista Chilena de Derecho (Vol. 35, № 1), pp. 85-106.

BARROS, ENRIQUe (1984): “Reglas y Principios en el Derecho", en: Anuario de Filosofía Jurídica y Social, pp. 269-281. 
(2006): Tratado de Responsabilidad Extracontractual (Santiago, Editorial Jurídica de

Chile).

BIDART, JOSÉ (1985): Sujetos de la acción de responsabilidad extracontractual (Santiago, Editorial Jurídica de Chile).

BosCH, ANTONI (1975): El daño (Barcelona, Casa Editorial S.A.).

BULYGIN, EUgenIo (2003): “Los jueces ¿crean derecho?", en: Malem, Jorge (Comp.), La función judicial, ética y democracia (Barcelona, editorial Gedisa), pp. 21-37.

Congreso NACIONAL (2017): “Historia de la Ley №21.018", en: BCN. Disponible en: https://bit.ly/3hPDGIV [visitado el 1 de agosto de 2020].

CORRAL, HERnÁN (2004): Lecciones de Responsabilidad Civil Extracontractual (Santiago, Editorial Juridica de Chile).

(2010): "Concurrencia de acciones de Responsabilidad civil Contractual y extracontractual en los daños causados por accidentes del trabajo", en: Revista Chilena de Derecho Privado (№ 14), pp. 69-107.

DíAZ, DENNISE (2017): "Por la transmisibilidad de la acción a favor de los herederos para reclamar el daño moral de su causante", en: Revista de Derecho Universidad de Concepción (Vol. 85, № 241), pp. 99-125.

Domínguez, CARMEn (2000): El daño moral (Santiago, Editorial Jurídica de Chile).

Domínguez, RAMÓN (2002): "Comentarios de Jurisprudencia. Competencia civil para el conocimiento de la acción indemnizatoria por daño moral sufrido por causahabitantes del trabajador", en: Revista de Derecho Universidad de Concepción (№ 151), pp. 259-265.

(2004): "Sobre la transmisibilidad de la acción por daño moral", en: Revista Chilena de Derecho (Vol. 31, № 3), pp. 493-514.

DWORKIN, RONALD (1986): El Imperio de la Justicia, segunda edición (Traducc. Claudia Ferrari, Barcelona, Editorial Gedisa).

ENDICOTT, TIMOTHY (2006): La vaguedad en el derecho (Madrid, Editorial Dykinson).

GAMONAL, SeRgio (2013): El Principio de Protección del trabajador en la constitución chilena, en: Estudios Constitucionales (Vol. 11, № 1), pp. 425-458.

(2014): Fundamentos de Derecho Laboral, 4a edición (Santiago, Thomson Reuters).

Gamonal, Sergio y Rosado, CÉSAR (2014): "Protecting Workers as a Metter Principle: A Latin American View of U.S. Work Law", en: Washington University Global Studies Law Review (Vol. 13, № 4), pp. 605-665.

(2019): Principled labor law: U.S. labor law trough a Latin American method (New York, Oxford University Press).

Mazeaud, Henry; Mazeaud, León y Tunc, André (1962): Tratado teórico y práctico de la responsabilidad civil delictual y contractual (Traducc. Luis Alcalá-Zamora y Castillo, Buenos Aires, Ediciones Jurídicas Europa-América), volumen II, tomo 2.

MUNITA, ENRIQUE (2014): El principio protector y la regla del in dubio pro operario como criterio de interpretación de la norma laboral, en: Revista Chilena de Derecho del Trabajo y de la Seguridad Social (Vol. 5, № 10), pp. 85-94.

PALAVECINO, ClaUdio (2018): "Comentario a la sentencia de unificación de jurisprudencia sobre transmisibilidad del derecho a indemnización por daño moral", en: Cárdenas, Hugo (Ed.), 
Jurisprudencia Crítica Comentarios de Fallos 2015-2017 (Santiago, Rubicón Editores), pp. 119127.

PLÁ, AMÉRICO (2015): Los Principios del Derecho del Trabajo, 4ạ edición (Montevideo, Fundación de Cultura Universitaria).

RODRÍGUEZ, PABLO (1999): Responsabilidad Extracontractual (Santiago, Editorial Jurídica de Chile).

RIOSECO, ANDRÉS (2018): “¿Se transmite el daño moral? Comentario a la sentencia de la Corte Suprema de 27 de diciembre de 2016", en: Cárdenas, Hugo (Ed.), Jurisprudencia Crítica Comentarios de Fallos 2015-2017 (Santiago, Rubicón Editores), pp. 129-139.

SILVA, LUIS (2019): “El caso el despido indirecto y la suspensión del plazo: ¿̇Interpretación o creación judicial del derecho?, en: Revista lus et Praxis (Vol. 25, № 2), pp. 433-458.

StReeter, JoRge (1993): “Casos difíciles”, en: Revista de Ciencias Sociales (Vol. 38, № 1), pp. 197220.

\section{JURISPRUDENCIA CITADA}

Ximena Victoria Cipriana ÓRdenes SANTA ANA con EMPRESA Constructora FuenZalida y GonZález LIMITADA (2001): Corte de Apelaciones de Santiago 23 de mayo de 2001 (recurso de casación en la forma y procedimiento correspondiente), en: www.westlawchile.cl (Cita online: $\mathrm{CL} / J U R / 4343 / 2001)$.

ERIKa del Carmen Rivadeneira Carvajal contra Sociedad Legal Minera Milagro Uno de Matancilla (2003): Corte Suprema 19 de agosto de 2003 (recurso de casación en el fondo y procedimiento correspondiente), en: www.westlawchile.cl (Cita online: CL/JUR/3490/2003).

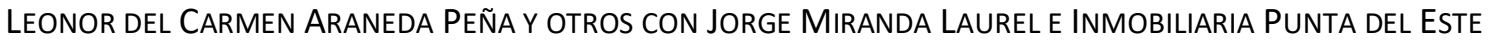
S.A. (2003): Corte de Apelaciones de Concepción 30 de septiembre de 2003 (recurso de apelación y procedimiento correspondiente), Rol № 1729-2003, en: base de datos del Poder Judicial www.pjud.cl.

Ruz Isabel alarcón durán y otros contra Jaime ramiro Corona Aravena (2006): Corte de Apelaciones de Concepción 26 de abril de 2006 (recurso de apelación y procedimiento correspondiente), en: www.westlawchile.cl (Cita online: CL/JUR/1318/2006).

Lucía Porman Barahona y otros contra Empresa Pesquera Bío Bío (2007): Corte Suprema 27 de junio de 2007 (recurso de casación en el fondo y procedimiento correspondiente), Rol № 3092006, en: www.vlex.cl.

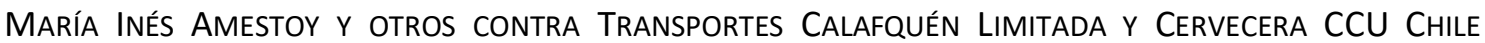
LIMITADA (2007): Corte Suprema 27 de noviembre de 2007 (recurso de casación en la forma y en el fondo, procedimiento correspondiente), en: www.microjuris.com (Cita: ROL6196-06, MJJ16221).

Elizabeth del Carmen Huentemil Fuentes y otros con Agro InVersiones S.A. (2007): Corte de Apelaciones de Concepción 12 de diciembre de 2007 (recurso de casación en la forma, procedimiento correspondiente), en: www.microjuris.com (Cita: ROL423-07, MJJ16442).

YeSENIA Cuevas Alarcón CON Industria ForeStal NACIONAL S.A. (2008): Corte Suprema 20 de agosto de 2008 (recurso de casación en la forma y procedimiento correspondiente), Rol № 3337-2008, en: www.vlex.cl.

Ricardo Mellao Calfuan y otros con Fisco de Chile (2011): Corte Suprema 29 de septiembre de 2011 (recurso de casación en el fondo y procedimiento correspondiente), Rol № 2073-2009, en: www.vlex.cl. 
Susana Lillo Cuevas con Ramón Cuello CarRasco y otros (2011): Corte de Apelaciones de Santiago 8 de noviembre de 2011 (recurso de apelación y procedimiento ordinario), Rol № 1910-2011, en: www.vlex.cl.

JoRdana Angélica Pérez Ramírez y otros con Monasterio SAN José de las CLARISAS y otro (2015): Corte de Apelaciones de Concepción 30 de marzo de 2015 (recurso de apelación y procedimiento correspondiente), Rol № 14-2015, en: base de datos del Poder Judicial www.pjud.cl.

María Clarisa Quezada Gallardo con Colmenares Werner Limitada (2016): Segundo Juzgado de Letras del Trabajo de Buin 28 de enero de 2016 (acción de indemnización de perjuicios por accidente de trabajo, procedimiento de aplicación general), Rit № 0-37-2015, en: www.vlex.cl.

CRistian Ignacio hormazabal Alcaíno y otros con Constructora TerRanoble limitada y otros (2016): Corte de Apelaciones de La Serena 21 de abril de 2016 (recurso de nulidad y acción de indemnización de perjuicios por accidente de trabajo, procedimiento de aplicación general), Rol № 16-2016, en: base de datos del Poder Judicial www.pjud.cl.

juan Edulio Caipillán Millalonco y FloRinda del Carmen Tipaina Guichapani con María Antonio ARISMENDI CARIMONEI (2016): Corte Suprema 26 de septiembre de 2016 (recurso de unificación de jurisprudencia y acción de indemnización de perjucios por accidente del trabajo, procedimiento de aplicación general), en: www.microjuris.cl (Cita: ROL:15206-15, MJJ47030).

María Clarisa Quezada Gallardo con Colmenares Werner Limitada (2016): Corte Suprema 27 de diciembre de 2016 (recurso de unificación de jurisprudencia y acción de indemnización de perjuicios por accidente de trabajo, procedimiento de aplicación general), Rol № 33990-2016, en: www.vlex.cl.

María Elena MaRdones Alvarado con Áridos y Contrucciones Socal LIMITAda (2017): Juzgado de Letras y Garantía de Paillaco 8 de junio de 2017 (acción de indemnización de perjuicios por accidente de trabajo, procedimiento de aplicación general), Rit № 0-2-2017, en: www.vlex.cl.

Escuela ESPECIAL de Lenguaje SANTA LeONOR Limitada con Verónica Nicol Vallejos Figueroa (2017): Corte de Apelaciones de Concepción 30 de junio de 2017 (recurso de nulidad y acción de desafuero, procedimiento de aplicación general), en: www.microjuris.cl (Cita: ROL152-17, MJJ50538).

Carmen Gloria navarro Moraga y Otros con Comercializadora Carlos Andrés Jofre Guitiérrez EIRL Y AGRícola CAUQueNeS LIMITAdA (2017): Juzgado de Letras del Trabajo de Curicó, 30 de noviembre de 2017 (acción de indemnización de perjuicios por accidente de trabajo, procedimiento de aplicación general), en: www.microjuris.com (Cita: RIT:0-132-2017, MJJ281763).

Benigna Rosa Ortega Céspedes y Erique Peralta Ortega con Corporación Agrícola S.A. (2018): Juzgado de Letras del Trabajo de San Felipe 9 de febrero de 2018 (acción de indemnización de perjuicios por accidente de trabajo, procedimiento de aplicación general), en: www.microjuris.com (Cita: RIT:O-176-2017, MJJ279188).

ERna Victoria Pérez Salinas Y OtRos CON TRANSPORTE de ÁRIDOS Y MOVIMIENTOS de TIERRAS MoRA LIMITADA Y OTROS (2018): Primer Juzgado de Letras del Trabajo de Santiago 20 de febrero de 2018 (acción de indemnización de perjuicios por accidente de trabajo, procedimiento de aplicación general), en: www.microjuris.com (Cita: RIT: O-88-2017, MJJ267193).

NATALI CÁRCAMO CÁRCAMO Y OTROS CON ÍCONO DIVISÓN DE TURISMO S.A. (2018): Corte Suprema 1 de marzo de 2018 (recurso de casación en el fondo y procedimiento correspondiente), Rol № 27842-2017, en: www.westlawchile.cl. 
Victoria Isabel Rosende Rasse y Pablo Marcelo Rosende Gómez con Codelco Chile División Andina (2018): Primer Juzgado de Letras de Los Andes 10 de abril de 2018 (acción de indemnización de perjuicios por accidente de trabajo, procedimiento de aplicación general), en www.microjuris.com (Cita: RIT:0-2629-2017, MJJ208001).

CONTRA KURT SCNELLEMKAMP NeLAIMISCHKIES Y OTROS (2018): Corte Suprema 22 de mayo de 2018 (recurso de casación en la forma y en el fondo, procedimiento correspondiente), Rol № 216142017, en: www.vlex.cl.

RAMÓN EdUARDO IBÁÑEZ ÁlVAREZ Y OTROS CON FORESTAL RUSSFIN LIMITADA (2018): Juzgado de Letras del Trabajo de Punta Arenas 29 de junio de 2018 (acción de indemnización de perjuicios por accidente de trabajo, procedimiento de aplicación general), en: www.microjuris.com (Cita: RIT:O-148-2017, MJJ273421).

Alberto Eugenio Veliz Peña con TActica S.A. y Claro Chile S.A. (2018): Primer Juzgado de Letras del Trabajo de Santiago 3 de diciembre de 2018 (acción de indemnización de perjuicios por enfermedad profesional, procedimiento de aplicación general), Rit № 0-1873-2018, en: www.vlex.cl.

Aurora del Carmen Soto NúÑez y Otros Con SOCIedAd Agrocomercial Fruchac S.A. y Otros (2018): Juzgado de Letras de La Calera 28 de diciembre de 2018 (acción de indemnización de perjuicios por accidente de trabajo, procedimiento de aplicación general), Rit № 0-44-2018, en: base de datos del Poder Judicial www.pjud.cl.

Lorena Alejandra Salas Morales y Otros con BHP ChILE INC. y Otros (2019): Primer Juzgado de Letras del Trabajo de Santiago 22 de marzo de 2019 (acción de indemnización de perjuicios por accidente del trabajo), Rit № 0-93-2018, en: www.vlex.cl.

karla andrea salviat figueroa y María Rosa del Carmen molina Guitiérrez con empresa Constructora PeCSA CHILE S.A. (2019): Corte Suprema 4 de abril de 2019 (recurso de casación en la forma y fondo, procedimiento correspondiente), Rol № 27948-2017, en: www.vlex.cl. 